\title{
Disseminação de práticas de segurança e saúde do trabalho entre empresas de construção por meio de ambientes colaborativos de aprendizagem
}

\author{
Disseminating health and safety practices among \\ construction companies through collaborative learning \\ environments
}

\section{Fabricio Borges Cambraia \\ Thales William Santana dos Santos Elvira Maria Vieira Lantelme}

\section{Resumo}

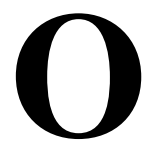

$\mathrm{s}$ ambientes colaborativos de aprendizagem representam uma oportunidade para a disseminação de práticas de segurança e saúde do trabalho entre empresas de construção, o que favorece o desenvolvimento local e regional. Contudo, pouco se conhece acerca dos fatores que determinam o sucesso desse processo de aprendizagem. Nesse sentido, o presente artigo tem como objetivo identificar um conjunto de fatores que contribuem para o processo de disseminação de práticas de segurança e saúde no trabalho entre um grupo de empresas de construção envolvidas em um ambiente colaborativo de aprendizagem. Com base na observação e avaliação das estratégias utilizadas na condução desse ambiente colaborativo e das práticas implantadas pelas empresas participantes durante o programa e avaliadas após seis meses de seu término, foram identificados dez fatores que contribuíram para a disseminação de práticas entre as empresas. Esses fatores podem ser utilizados para orientar o desenvolvimento de novos ambientes colaborativos com objetivos semelhantes e promover o desenvolvimento local de empresas de construção civil de pequeno porte.

Palavras-chave: Segurança e Saúde do Trabalho. Ambientes colaborativos. Construção civil. Desenvolvimento local.

Fabricio Borges Cambraia Universidade Federal de Juiz de Fora Juiz de Fora - MG - Brasil

Thales William Santana dos

Santos Companhia de Saneamento de Sergipe Aracaju - SE - Brasil

Elvira Maria Vieira Lantelme Faculdade Meridional Passo Fundo - RS - Brasil

Recebido em 06/05/16 Aceito em 11/10/16

\section{Abstract}

Collaborative learning environments are an opportunity to disseminate health and safety practices among construction companies, favouring local and regional development. However, little is known about the factors that determine the success of this learning process. Thus, this article aims to identify a set of factors that contribute to the process of disseminating health and safety practices among a group of construction companies involved in a collaborative learning environment. Based on the observation and evaluation of the strategies used in conducting this collaborative environment and the practices implemented by the companies during the program and followed up after six months of its completion, ten factors were identified that contributed to disseminating practices among the participating companies. These factors can guide the development of new collaborative learning environments with similar objectives and promote local development of small construction companies.

Keywords: Safety and health. Collaborative environments. Construction. Local development. 


\section{Introdução}

A construção civil é um dos setores de grande importância econômica para a maioria dos países e também um dos que lidera o ranking de acidentes e óbitos no trabalho. No Brasil o setor teve um crescimento de $9,62 \%$ dos postos formais de trabalho entre os anos de 2010 e 2011 (BRASIL, 2011a), sendo responsável também por um aumento de 6,95\% no número de acidentes comparativamente ao ano anterior, totalizando 59.808 acidentes (BRASIL, 2011b).

Entre as estratégias para a redução de acidentes do trabalho na construção pode-se citar a adoção de práticas de segurança e saúde do trabalho (SST). Uma prática de SST é definida por Bridi et al. (2013) como um processo gerencial que pode empregar uma ou mais técnicas e ferramentas, obrigatória pela legislação ou voluntária, e cujo objetivo é contribuir para o controle de riscos relacionados à SST. A adoção dessas práticas, além de ser muitas vezes uma obrigação legal, se constitui em atividades de natureza técnica, administrativa e econômica para a organização e de inestimável benefício para os empregados, suas famílias e sociedade.

A adoção e o uso efetivo de práticas de SST são encarados como uma necessidade latente no setor, visto que sua falta ou deficiências de uso são fatores que podem impactar negativamente nos índices de acidentes (AWWAD; EL SOUKI; JABBOUR, 2016; RAZURI, 2007; HINZE, 2002). Assim, nas últimas décadas, muito se tem estudado sobre o tema, de forma a identificá-lo e a entender, por exemplo, os fatores que contribuem para o sucesso de programas de prevenção de acidentes (BRIDI et al., 2013; HINZE, 2002).

Contudo, no âmbito dessas pesquisas, pouco se conhece especialmente sobre o processo de disseminação das práticas de SST, provavelmente pelo fato de serem restritas predominantemente às empresas de grande porte ou aos estudos acadêmicos descritivos. Esse cenário pode representar, por exemplo, dificuldades de apropriação das práticas, principalmente em empresas de menor porte e recursos. Isso sinaliza para a busca de estratégias que possibilitem às empresas a aquisição de novos conhecimentos, de forma a melhorar continuamente seus desempenhos, sem necessidade de grandes investimentos.

Nesse sentido, um caminho pode ser o emprego de mecanismos que facilitem o compartilhamento e disseminação de conhecimento entre empresas de construção de portes diferentes. Costa e Formoso (2011), por exemplo, sugerem o desenvolvimento de ambientes colaborativos de aprendizagem como um dos meios para a disseminação de boas práticas entre empresas construtoras. Florén (2003) afirma que as abordagens colaborativas de aprendizagem apresentam-se mais adequadas aos gerentes de pequenas empresas. Isso se deve à falta de tempo e recursos para investir em processos de desenvolvimento e aprendizagem formais, como também à falta de parceiros dentro da própria empresa com quem possam refletir e trocar informações, em função da própria estrutura organizacional reduzida. Como consequência, há falta de diferentes perspectivas e visões para a análise e busca de soluções para as situações vivenciadas.

Dessa forma, os ambientes colaborativos de aprendizagem, também referidos como redes de cooperação ou redes de aprendizagem (BALESTRIN; VERSHOORE, 2008), são ambientes que favorecem a interação entre pessoas, grupos e organizações, possibilitando, por meio do compartilhamento de práticas, processos, cultura e diferenças, a aprendizagem e o desenvolvimento organizacional. Além disso, podem ser vistos como formas de incentivar a disseminação de boas práticas gerenciais ou tecnológicas entre empresas que atuam em ramos de negócio similares, o que favorece a troca de informações e conhecimentos, a aprendizagem e a inovação (POPP et al., 2013).

Popp et al. (2013) concluem a partir de uma ampla revisão de literatura sobre as redes colaborativas de aprendizagem que, embora o processo de concepção e a implantação dos ambientes colaborativos tenham sido amplamente estudados em diferentes contextos de aplicação, persistem na literatura lacunas de conhecimentos no que se refere ao processo de transferência do conhecimento e aprendizagem, bem como sobre as estratégias de gerenciamento dentro desses ambientes.

Nesse sentido, este trabalho parte da premissa de que a criação de um ambiente colaborativo para troca de práticas de SST entre empresas de construção pode representar um meio eficaz para disseminação dessas práticas no setor e a consequente melhoria da segurança e saúde do trabalhador da construção civil. Assim sendo, a partir da estruturação e operação de um ambiente colaborativo, formado por um grupo de empresas atuantes no setor da construção civil, este artigo objetiva identificar os fatores que contribuem para o processo de disseminação de práticas de SST entre as empresas participantes. 


\section{Ambientes colaborativos de aprendizagem}

A ideia de aprendizagem por meio da colaboração vem sendo estudada tanto sob o ponto de vista das redes de cooperação e formação de alianças estratégicas colaborativas entre empresas, enfatizando os novos arranjos interorganizacionais em busca de melhoria de competitividade e inovação (BALESTRIN; VERSHOORE, 2008; BESSANT; TSEKOURAS, 2001; WOOD; GRAY, 1991), quanto sob o ponto de vista da aprendizagem organizacional por meio de processos sociais de compartilhamento de conhecimento (FLORÉN, 2003; NONAKA; TAKEUCHI, 1997; PETER et al., 2010).

Wood e Gray (1991) identificaram que não existe um consenso sobre o significado de colaboração nessas abordagens, mas, observando os elementos em comum entre as definições apresentadas pelos autores investigados em sua pesquisa, propõem a seguinte definição:

\section{[...] a colaboração ocorre quando um grupo autônomo [individualmente ou representando suas empresas] de posse de um problema comum se engaja em um processo interativo, compartilhando normas, regras e estruturas, para agir ou decidir sobre questões relacionadas ao problema [...]. (WOOD; GRAY, 1991, p. 146, tradução nossa).}

Três questões podem ser destacadas nessa definição:

(a) a necessidade de um problema comum, que gera o interesse e engajamento dos indivíduos ou empresas;

(b) a interação, que possibilita que ocorram as trocas, as reflexões e a aprendizagem em grupo; e

(c) as normas, regras e estruturas que favorecem a interação e a colaboração.

Nesse mesmo sentido, Balestrin e Vershoore (2008) identificam três condições para o estabelecimento de redes de cooperação: objetivos comuns, interação e gestão.

Balestrin e Vershoore (2008) colocam que os objetivos comuns compartilhados pelos participantes podem ser os mais diversos, desde a necessidade de acesso a informações e recursos que possam auxiliar na busca de soluções para as dificuldades das empresas, passando pela possibilidade de ampliação de poder e influência ou de ampliação da capacidade de ação; o compartilhamento de ideias e experiências que possibilitem a introdução de inovações, a redução de custos e riscos; a ampliação de relações sociais entre os membros do grupo, para além das puramente econômicas, entre outros. São os objetivos comuns que levam aos diferentes possíveis arranjos e estruturas que esses ambientes colaborativos podem tomar.

Os citados autores ainda afirmam que a simples existência de objetivos comuns não é suficiente para garantir a aprendizagem colaborativa. Para a formação de um ambiente colaborativo de aprendizagem deve haver um efetivo processo de interação entre os membros do grupo. Os ambientes colaborativos criam um espaço de aprendizagem social. $\mathrm{O}$ processo social de aprendizagem implica a aprendizagem com e através do outro. Dessa forma, o foco encontra-se nas estruturas de participação e relacionamentos interpessoais, por meio das quais ocorrem as trocas de informações e conhecimentos, e a aprendizagem adquire significado (ELKJAËR, 1999; LAVE; WENGER, 1991; NONAKA; TAKEUCHI, 1997; SOUZA, 2007).

Por outro lado, Balestrin e Vershoore (2008) e Wood e Gray (1991) ressaltam a importância da competência do gestor ou organizador da rede em utilizar-se de estratégias que favoreçam a colaboração e aprendizagem social. Britto (2001) enfatiza que mecanismos formais e informais de aprendizagem ocorridos dentro do ambiente colaborativo, bem como suas regras de funcionamento, influenciam a receptividade dos participantes em relação aos estímulos surgidos durante sua operação. Freitas e Heineck (2014), por sua vez, frisam que o aumento da receptividade das empresas facilita o intercâmbio de conhecimentos e informações entre elas, o que faz com que o conhecimento adquirido por uma possa ser transferido para as outras.

Entretanto, conforme destacado por Freitas e Heineck (2014), a aprendizagem ocorre dentro da rede por meio de um processo de interação, mas seus impactos são sentidos individualmente, já que cada empresa tem uma trajetória própria de aprendizagem. Essa aprendizagem particular pode ser compreendida a partir do conceito de capacidade de absorção. Segundo Cohen e Levinthal (1990), precursores do conceito, para absorver novos conhecimentos a empresa necessita de uma base de conhecimentos e habilidades prévias relacionadas. Outros fatores como confiança, resistência por parte dos participantes e posição ocupada na rede foram destacados por Freitas e Heineck (2014).

Considera-se, portanto, que a disseminação das práticas de SST por meio de ambientes colaborativos de aprendizagem é um processo que 
implica, por um lado, a preocupação com as estratégias que favoreçam a transferência de conhecimentos e a interação social dentro do ambiente colaborativo, visando ao compartilhamento de práticas, e, por outro lado, os conhecimentos e habilidades individuais de seus participantes, que caracterizam sua capacidade de absorção ou aprendizagem dessas práticas.

\section{Método de pesquisa}

A estratégia de pesquisa utilizada neste trabalho foi o estudo de caso, escolhida por buscar a compreensão aprofundada do processo de disseminação de práticas de SST ocorridas por meio da participação das empresas em um ambiente colaborativo de aprendizagem. A fim de garantir a qualidade técnica e científica do estudo, conforme sugere Yin (2005), os dados do estudo foram coletados com uso de múltiplas fontes de evidência: observação direta, observação participante, análise de documentos, relatos formais dos participantes durante os encontros e entrevistas realizadas após a conclusão do estudo. Da mesma forma, procurou-se a colaboração de pesquisadores externos que auxiliaram na análise dos dados a fim de garantir uma convergência de interpretações.

O estudo foi delineado em três etapas de pesquisa. A primeira etapa, denominada Estruturação, teve por objetivo criar a estrutura formal do ambiente colaborativo, visando à participação e ao alinhamento de interesses das empresas. Essa etapa foi desenvolvida seguindo as diretrizes propostas no trabalho de Costa (2008). Os contatos iniciais com as empresas foram realizados a partir de uma parceria com o Sindicato da Indústria da Construção Civil de Sergipe (Sinduscon/SE), o que favoreceu a adesão e o alinhamento de interesses das empresas aos objetivos do estudo.
Nessa etapa foi realizado um diagnóstico nas empresas participantes com a aplicação de um checklist da NR-18 (MALLMANN et al., 2009) e de entrevistas com representantes das empresas (CAMBRAIA et al., 2013). Participaram dessa etapa dez empresas, caracterizadas por diferentes portes e focos de atuação, com idade mínima de 10 e máxima de 55 anos no mercado, que realizavam empreendimentos de diferentes graus de complexidade. O checklist foi aplicado em 22 empreendimentos em construção, alcançando-se o índice de adequação à NR-18 (INR-18), métrica esta proposta por Saurin, Lantelme e Formoso (2000), cujos resultados são apresentados na Figura 1.

As entrevistas envolveram profissionais das áreas de produção (engenheiros de obras) e de segurança (engenheiros e técnicos) visando levantar a percepção desses intervenientes quanto aos fatores críticos para o atendimento da NR-18 (BRASIL, 2015). Os questionamentos abordaram:

(a) itens considerados de maior dificuldade de atendimento;

(b) itens considerados de maior cobrança por parte dos auditores fiscais; e

(c) itens considerados de maior relevância à prevenção dos acidentes.

Ao todo foram realizadas 51 entrevistas, $20 \mathrm{com}$ engenheiros de obra, 26 com técnicos de segurança e 5 com engenheiros de segurança. O Quadro 1 mostra os fatores críticos identificados e a análise realizada. Os fatores que aparecem com maior frequência foram considerados prioritários na definição das temáticas dos encontros do ambiente colaborativo. Os resultados da análise conjunta das entrevistas e do INR-18 (SAURIN; LANTELME; FORMOSO, 2000) foram utilizados para definir os temas e estratégias para o desenvolvimento do ambiente colaborativo.

Figura 1 - Resultado comparativo, em ordem decrescente, do INR-18 das empresas ÍNDICE DE ADEQUAÇÃO À NR-18 (INR-18) DE CADA EMPRESA

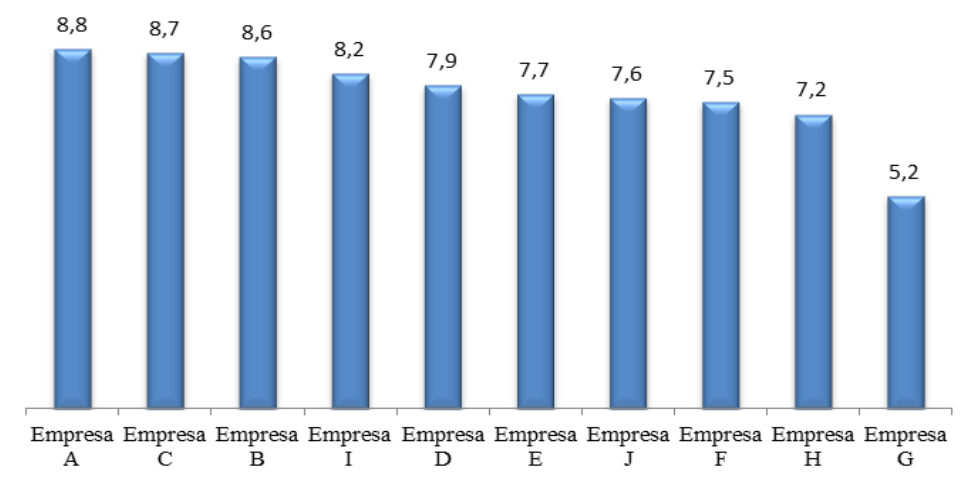

Fonte: Cambraia et al. (2013). 


\section{Quadro 1 - Fatores críticos analisados}

\begin{tabular}{|c|c|c|c|c|c|}
\hline $\begin{array}{l}\text { Maior dificuldade de } \\
\text { atendimento à NR18 }\end{array}$ & $\%$ & $\begin{array}{l}\text { Maior cobrança pela } \\
\text { fiscalização }\end{array}$ & $\%$ & $\begin{array}{c}\text { Relevante importância } \\
\text { para a prevenção de } \\
\text { acidentes }\end{array}$ & $\%$ \\
\hline EPC & 26 & EPC & 29 & EPC & 23 \\
\hline EPI & 15 & $\begin{array}{l}\text { Manutenção e adequação } \\
\text { das áreas de vivência }\end{array}$ & 19 & EPI & 18 \\
\hline $\begin{array}{l}\text { Manutenção e adequação das } \\
\text { áreas de vivência }\end{array}$ & 14 & $\begin{array}{l}\text { Elaboração e controle de } \\
\text { documentação }\end{array}$ & 17 & $\begin{array}{l}\text { Planejamento, execução e } \\
\text { avaliação de treinamentos }\end{array}$ & 16 \\
\hline $\begin{array}{l}\text { Planejamento, execução e } \\
\text { controle de máquinas e } \\
\text { equipamentos }\end{array}$ & 11 & $\begin{array}{l}\text { Planejamento, execução e } \\
\text { controle de máquinas e } \\
\text { equipamentos }\end{array}$ & 14 & $\begin{array}{l}\text { Planejamento, execução e } \\
\text { controle de máquinas e } \\
\text { equipamentos }\end{array}$ & 10 \\
\hline $\begin{array}{l}\text { Organização, sinalização e } \\
\text { limpeza da obra }\end{array}$ & 9 & EPI & 10 & $\begin{array}{l}\text { Mão de obra e } \\
\text { comportamento }\end{array}$ & 8 \\
\hline $\begin{array}{l}\text { Planejamento, execução e } \\
\text { avaliação de treinamentos }\end{array}$ & 8 & $\begin{array}{l}\text { Planejamento, execução e } \\
\text { avaliação de treinamentos }\end{array}$ & 3 & $\begin{array}{l}\text { Organização, sinalização } \\
\text { e limpeza da obra }\end{array}$ & 7 \\
\hline $\begin{array}{l}\text { Mão de obra e } \\
\text { comportamento }\end{array}$ & 8 & $\begin{array}{l}\text { Organização, sinalização e } \\
\text { limpeza da obra }\end{array}$ & 2 & $\begin{array}{l}\text { Elaboração e controle de } \\
\text { documentação }\end{array}$ & 6 \\
\hline $\begin{array}{l}\text { Elaboração e controle de } \\
\text { documentação }\end{array}$ & 4 & $\begin{array}{l}\text { Procedimentos de } \\
\text { medicina do trabalho }\end{array}$ & 2 & $\begin{array}{l}\text { Manutenção e adequação } \\
\text { áreas de vivência }\end{array}$ & 5 \\
\hline $\begin{array}{l}\text { Instalação e execução da } \\
\text { comissão interna de } \\
\text { prevenção de acidentes } \\
\text { (Cipa) }\end{array}$ & 3 & $\begin{array}{l}\text { Planejamento, execução e } \\
\text { manutenção de instalações } \\
\text { elétricas provisórias }\end{array}$ & 2 & Outros & 4 \\
\hline Outros & 3 & Outros & 1 & $\begin{array}{l}\text { Planejamento, execução e } \\
\text { manutenção de } \\
\text { instalações elétricas } \\
\text { provisórias }\end{array}$ & 3 \\
\hline
\end{tabular}

A segunda etapa da pesquisa consistiu no desenvolvimento e observação do ambiente colaborativo de aprendizagem, denominada de Operação. Foram feitas inicialmente visitas às empresas participantes para disseminação dos resultados do diagnóstico e busca pela adesão ao projeto. A adesão foi consolidada com a nomeação de representantes das empresas que iriam participar dos encontros. Cada empresa definiu uma dupla de representantes das áreas de segurança e produção. Do total de empresas da primeira etapa apenas duas optaram por não continuar no projeto.

$\mathrm{Na}$ fase de Operação do ambiente colaborativo foram realizados oito encontros quinzenais utilizando-se diferentes estratégias para compartilhamento de conhecimento, tais como apresentação de casos, mesas-redondas, visitas técnicas e palestras com especialistas. A agenda dos encontros pode ser vista no Quadro 2.

A coleta de dados durante a etapa de Operação do ambiente colaborativo baseou-se na observação participante, no registro dos relatos orais das empresas em cada encontro e nos documentos apresentados pelas empresas durante os encontros. Todas as reuniões foram gravadas em áudio, com permissão dos participantes. No início de cada encontro os participantes eram convidados a apresentar um relato das ações tomadas entre as reuniões e formas utilizadas para disseminação das informações em suas empresas e obras. Esses relatos foram registrados pelos próprios participantes das empresas em uma folha A4 e também oralmente nos áudios dos encontros. Nos encontros os relatos consumiam de $20 \mathrm{~min}$ a 30 min. Especificamente no encontro 8, o registro consistiu nas anotações dos pesquisadores e na análise das apresentações realizadas pelas empresas no seminário final.

Buscou-se, dessa forma, identificar e descrever as práticas compartilhadas e aquelas implantadas pelas empresas durante a operação do ambiente e registrar as formas, obstáculos e oportunidades encontrados pelos participantes para a disseminação das práticas e informações compartilhadas dentro do ambiente colaborativo.

Essas ações foram posteriormente verificadas in loco, durante as visitas aos canteiros de obras e entrevistas com os participantes realizadas após 6 meses do término da segunda etapa do projeto. Foram realizadas entrevistas abertas com os participantes e visitas às obras para identificar as práticas implantadas, ou seja, as ações realizadas pelas empresas em função de sua participação no 
ambiente colaborativo, e verificar a percepção dos participantes quanto ao processo de aprendizagem e compartilhamento ocorrido durante e após sua operação. As entrevistas foram gravadas com permissão dos entrevistados e posteriormente transcritas.

A terceira etapa da pesquisa consistiu na análise dos dados e proposição de fatores que contribuíram para o processo de disseminação de práticas de SST pelas empresas participantes do ambiente colaborativo. O processo de análise de dados iniciou-se ainda na fase de coleta de dados, ou seja, durante a fase de operação do ambiente colaborativo, e baseou-se na metodologia grounded theory (MILES; HUBERMAN, 1994), embora não a tenha seguido formalmente em todas as etapas. Tomando por base o objetivo da pesquisa e a revisão inicial de literatura, foram elaborados alguns constructos iniciais sobre os fatores que poderiam influenciar o processo de disseminação de práticas entre as empresas participantes. Ao longo da operação do ambiente colaborativo, os pesquisadores buscaram anotar evidências que confirmassem esses constructos e evidenciá-los com base nos extratos das transcrições dos encontros e corroborá-los por meio de revisões de literatura mais focadas.

\section{Quadro 2 - Agenda final dos encontros do ambiente colaborativo}

\begin{tabular}{|c|c|}
\hline Assunto do encontro & Formatos e expositores \\
\hline $\begin{array}{l}\text { Encontro 1: } \\
\text { Contrato de funcionamento } \\
\text { e apresentação dos } \\
\text { participantes }\end{array}$ & $\begin{array}{l}\text { Palestra: Sistemas de gestão e prática de SST. Facilitador: coordenador } \\
\text { do projeto } \\
\text { Apresentação do diagnóstico pela equipe do projeto e escolha dos temas } \\
\text { Apresentação e discussão da proposta inicial do programa }\end{array}$ \\
\hline $\begin{array}{l}\text { Encontro 2: } \\
\text { EPC: medidas de proteção } \\
\text { contra queda de altura }\end{array}$ & $\begin{array}{l}\text { Motivação inicial e discussão do tema. Facilitador: Coordenador do } \\
\text { Projeto } \\
\text { Exposição de caso 1: Empresa A (EPC utilizados e práticas gerenciais } \\
\text { de suporte) } \\
\text { Exposição de caso 2: Empresa C (linha de vida }{ }^{1} \text { ou técnica do varal) }\end{array}$ \\
\hline $\begin{array}{l}\text { Encontro 3: } \\
\text { Máquinas e equipamentos }\end{array}$ & $\begin{array}{l}\text { Visita técnica na Empresa C: (a) requisitos de segurança em elevadores } \\
\text { e serra circular com suas práticas gerenciais de suporte e (b) aplicação } \\
\text { prática dos tubos para linha de vida }\end{array}$ \\
\hline $\begin{array}{l}\text { Encontro 4: } \\
\text { Dificuldades enfrentadas } \\
\text { para proteção de aberturas } \\
\text { de piso, treinamentos e EPI }\end{array}$ & $\begin{array}{l}\text { Mesa-redonda: representantes das Empresas B, F e H e participação, } \\
\text { como debatedor, de um especialista em SST } \\
\text { Exposição de caso: Empresa A (boas práticas de treinamentos) }\end{array}$ \\
\hline $\begin{array}{l}\text { Encontro 5: } \\
\text { Andaimes: dificuldades, } \\
\text { obrigatoriedades e práticas } \\
\text { gerenciais de suporte }\end{array}$ & $\begin{array}{l}\text { Mesa-redonda: representantes das Empresas C, D e G e participação, } \\
\text { como debatedor, de um especialista em SST } \\
\text { Palestra técnica: auditor fiscal do trabalho (andaimes: exigências legais, } \\
\text { principais irregularidades e boas práticas) }\end{array}$ \\
\hline $\begin{array}{l}\text { Encontro 6: } \\
\text { Práticas gerenciais para } \\
\text { organização, sinalização e } \\
\text { limpeza da obra }\end{array}$ & $\begin{array}{l}\text { Visita técnica na Empresa A: boas práticas de organização, sinalização e } \\
\text { limpeza de obra (áreas de vivência) } \\
\text { Palestra técnica: engenheiro ambiental da Empresa A (o canteiro } \\
\text { sustentável) }\end{array}$ \\
\hline $\begin{array}{l}\text { Encontro 7: } \\
\text { Integração, segurança e } \\
\text { produção: dificuldades e } \\
\text { possibilidades }\end{array}$ & $\begin{array}{l}\text { Mesa-redonda: representantes das Empresas A e B (engenheiros de } \\
\text { produção), além da participação do coordenador do projeto como } \\
\text { debatedor: planejamento e controle da produção } \\
\text { Apresentação de um caso de sucesso: integração entre planejamento e } \\
\text { controle da segurança - Coordenador do Projeto }\end{array}$ \\
\hline $\begin{array}{l}\text { Encontro 8: Após } 1 \text { mês do } \\
\text { encontro anterior } \\
\text { Apresentação dos } \\
\text { resultados } \\
\text { Seminário aberto à } \\
\text { comunidade }\end{array}$ & $\begin{array}{l}\text { Seminário de apresentação de ganhos/dificuldades decorrentes da } \\
\text { participação no ambiente colaborativo pelas empresas participantes }\end{array}$ \\
\hline
\end{tabular}

${ }^{1}$ As linhas de vida são equipamentos de proteção coletiva, constituídas por tubos metálicos ancorados em, no mínimo duas lajes, que servem para conexão dos cintos de segurança em serviços como montagem de fôrmas e concretagem, entre outros. 
Por outro lado, novos constructos emergiram durante a operação do ambiente colaborativo, durante as entrevistas e visitas às obras, e durante a análise dos dados coletados propriamente dita. Assim, cada novo constructo estabelecido implicou um aprofundamento na revisão de literatura e na identificação de evidências, seja nas falas dos participantes, nas declarações das entrevistas, nas ações implementadas em obras ou nas anotações dos pesquisadores. Durante esse processo alguns dos constructos iniciais foram desconsiderados, por falta de evidências que pudessem confirmá-los.

Esse processo foi realizado em vários ciclos repetitivos de leitura dos dados e revisão da literatura, até que os pesquisadores chegassem à conclusão de terem atingido sua total abrangência. Nessa fase do processo as análises foram submetidas à avaliação de um pesquisador externo com experiência na área de aprendizagem colaborativa, que realizou contribuições referentes à coerência entre construtos e evidências levantadas.

Com base nesses constructos, os resultados da pesquisa foram generalizados em dez fatores, que contribuíram para a disseminação de práticas de SST, procurando-se apresentar para cada um deles as argumentações teóricas e as evidências mais marcantes relacionadas ao estudo de caso.

\section{Práticas de SST absorvidas nas empresas}

O Quadro 3 apresenta as práticas implantadas pelas empresas e descritas em função do tema dos encontros realizados.

A Empresa A participou de todos os encontros, tendo enviado tanto seus representantes da segurança quanto da produção, aproveitando sua participação no projeto principalmente para a capacitação de seus profissionais, bem como para a realização de ajustes em alguns procedimentos de trabalho. Os gestores possuíam grande autonomia e poder de decisão para intervenção nas questões ligadas à segurança. Além disto, essa empresa participou ativamente durante os encontros, difundido práticas que serviram de referência para as demais empresas. Cabe destacar que algumas dessas práticas receberam premiações em âmbito nacional. Internamente, os conhecimentos adquiridos foram difundidos para toda a empresa por meio de um jornal periódico interno, das reuniões de rotina e de treinamentos específicos.

As práticas absorvidas pela Empresa B, no geral, se caracterizam por serem de baixo custo e concretizadas pelo Serviço Especializado em
Engenharia e Medicina do Trabalho (SESMT), com apoio, em especial, de um engenheiro mecânico, particularmente quanto às melhorias na gestão de máquinas e equipamentos. Os entrevistados salientaram as limitações encontradas para a implantação de novas práticas quando estas demandavam investimentos financeiros por parte da direção da empresa.

Exceto a revisão em detalhes técnicos das linhas de vida, as práticas implantadas pela Empresa C foram ligadas à gestão da SST, como alocação de um técnico de segurança para tarefas gerenciais, desenvolvimento de uma base de dados de indicadores de SST e organização de uma agenda de treinamentos. Nesta empresa observou-se grande envolvimento dos representantes da área de segurança, porém foram relatadas resistências quando a implantação de novas práticas requeria o envolvimento da área de produção.

A Empresa D foi a que implantou o maior número de práticas, em decorrência principalmente do apoio, investimento e participação direta da direção na divulgação das informações durante a operação do ambiente colaborativo. Entre essas ações pode-se citar a maior autonomia dada para os técnicos de segurança intervirem em processos irregulares, a alocação de um especialista em SST para gerir o setor e a contratação de um engenheiro mecânico para assessoramento nas questões ligadas a máquinas e equipamentos.

A Empresa E engajou-se muito pouco nas atividades propostas no ambiente colaborativo, tendo apresentado baixa frequência e envolvimento de seus gestores nos encontros. $\mathrm{O}$ representante da área de produção, por exemplo, teve dificuldades de participar dos encontros pela priorização de outras atividades por seu gestor superior, que era o representante da área de segurança. $O$ engenheiro de segurança dessa empresa, que atuava em tempo parcial, declaradamente não considerava a participação nos encontros importante. Assim, a representação da segurança restringiu-se aos técnicos, que dispunham de baixo poder de decisão e autonomia em relação à implantação de mudanças.

A participação da Empresa $\mathrm{F}$ aconteceu essencialmente pela presença de seu engenheiro de segurança. Os conhecimentos adquiridos permitiram ao engenheiro maior embasamento técnico-financeiro nas negociações com a diretoria, o que possibilitou a implantação de algumas mudanças. Esse engenheiro ressaltou que aproveitou principalmente os momentos informais (coffee break, por exemplo) para adquirir informações específicas com os colegas, o que resultou, por exemplo, na aquisição de novos 
elevadores. O baixo engajamento da área de produção e de outros representantes da empresa nos encontros pode ter limitado a disseminação de outras práticas.

Quadro 3 - Práticas absorvidas pelas empresas

\begin{tabular}{|c|c|c|c|c|c|c|c|}
\hline & $\begin{array}{l}\text { EMPRESAS } \\
\text { PRÁTICAS }\end{array}$ & $\mathbf{A}$ & B & C & D & $\mathbf{E}$ & $\mathbf{F}$ \\
\hline 1 & $\begin{array}{l}\text { Palestra: ambiente } \\
\text { colaborativo e } \\
\text { enfoque sistêmico }\end{array}$ & $\begin{array}{c}\text { Treinamento } \\
\text { sobre os } \\
\text { paradigmas da } \\
\text { gestão de } \\
\text { segurança para } \\
\text { os especialistas } \\
\text { de SST } \\
\end{array}$ & Não identificado & $\begin{array}{l}\text { Alocação de } \\
\text { técnico de } \\
\text { segurança em } \\
\text { tarefas } \\
\text { exclusivamente } \\
\text { gerenciais }\end{array}$ & $\begin{array}{l}\text { Alocação de um } \\
\text { especialista em } \\
\text { segurança como } \\
\text { gestor da área }\end{array}$ & Não identificado & Não identificado \\
\hline 2 & $\begin{array}{l}\text { Proteção contra } \\
\text { quedas de altura }\end{array}$ & Não identificado & Não participação & Não identificado & $\begin{array}{c}\text { Criação e } \\
\text { capacitação de } \\
\text { uma equipe } \\
\text { específica para } \\
\text { execução de EPC }\end{array}$ & $\begin{array}{c}\text { Utilização de } \\
\text { guarda-corpo } \\
\text { metálico nas } \\
\text { periferias da obra } \\
\text { para prevenção } \\
\text { de quedas } \\
\end{array}$ & Não identificado \\
\hline 3 & $\begin{array}{c}\text { Maquinas e } \\
\text { equipamentos }\end{array}$ & Não identificado & $\begin{array}{c}\text { Revisão nos } \\
\text { procedimentos } \\
\text { referentes às } \\
\text { serras circulares } \\
\text { Sistematização } \\
\text { do controle } \\
\text { (instalação, } \\
\text { operação e } \\
\text { manutenção) nos } \\
\text { elevadores } \\
\text { Utilização de } \\
\text { telas metálicas } \\
\text { em áreas } \\
\text { periféricas para } \\
\text { prevenção contra } \\
\text { quedas de altura }\end{array}$ & $\begin{array}{l}\text { Revisão nos } \\
\text { procedimentos da } \\
\text { linha de vida }\end{array}$ & $\begin{array}{l}\text { Contratação de } \\
\text { um engenheiro } \\
\text { mecânico } \\
\\
\text { Criação de } \\
\text { rotinas de } \\
\text { controle } \\
\text { preventivo em } \\
\text { máquinas e } \\
\text { equipamentos }\end{array}$ & Não identificado & $\begin{array}{l}\text { Revisão nos } \\
\text { procedimentos da } \\
\text { linha de vida } \\
\\
\text { Desenvolvimento } \\
\text { de rotinas de } \\
\text { controle } \\
\text { preventivo para } \\
\text { os elevadores a } \\
\text { cabo }\end{array}$ \\
\hline 4 & $\begin{array}{l}\text { Abertura piso, } \\
\text { treinamento e EPI }\end{array}$ & Não identificado & $\begin{array}{l}\text { Padronização e } \\
\text { multiplicação em } \\
\text { todas as obras } \\
\text { dos treinamentos } \\
\text { periódicos }\end{array}$ & $\begin{array}{c}\text { Desenvolvimento } \\
\text { de base de dados } \\
\text { com indicadores } \\
\text { de desempenho } \\
\text { de SST } \\
\text { Organização de } \\
\text { agenda de } \\
\text { treinamentos } \\
\text { periódicos nas } \\
\text { obras }\end{array}$ & $\begin{array}{l}\text { Organização dos } \\
\text { treinamentos e } \\
\text { ampliação dos } \\
\text { conteúdos }\end{array}$ & Não participação & $\begin{array}{l}\text { Realização da } \\
\text { primeira SIPAT } \\
\text { da empresa }\end{array}$ \\
\hline 6 & $\begin{array}{c}\text { Organização, } \\
\text { sinalização e limpeza }\end{array}$ & Não identificado & $\begin{array}{c}\text { Revisão nos } \\
\text { projetos de } \\
\text { instalações } \\
\text { provisórias, com } \\
\text { a introdução de } \\
\text { telhas } \\
\text { transparentes e } \\
\text { aproveitamento } \\
\text { de resíduos de } \\
\text { peças cerâmicas } \\
\text { para } \\
\text { revestimento de } \\
\text { piso } \\
\\
\text { Criação do } \\
\text { "cantinho } \\
\text { seguro" }\end{array}$ & Não participação & $\begin{array}{l}\text { Atribuição de } \\
\text { responsabilidade } \\
\text { ao setor da } \\
\text { segurança pela } \\
\text { limpeza dos } \\
\text { canteiros } \\
\text { Implantação do } \\
\text { "cantinho } \\
\text { seguro" } \\
\text { Melhorias no } \\
\text { mural de SST das } \\
\text { obras } \\
\text { Melhorias nas } \\
\text { instalações } \\
\text { provisórias, que } \\
\text { passaram, por } \\
\text { exemplo, a ser } \\
\text { executadas em } \\
\text { alvenaria } \\
\end{array}$ & Não identificado & Não identificado \\
\hline 7 & $\begin{array}{c}\text { Interação, segurança } \\
\text { e produção }\end{array}$ & $\begin{array}{l}\text { Treinamento } \\
\text { sobre } \\
\text { planejamento } \\
\text { integrado entre } \\
\text { segurança e } \\
\text { produção para os } \\
\text { gestores de } \\
\text { produção e } \\
\text { especialistas de } \\
\text { SST } \\
\end{array}$ & Não identificado & Não identificado & $\begin{array}{c}\text { Participação dos } \\
\text { especialistas em } \\
\text { SST nas reuniões } \\
\text { de PCP } \\
\text { Elaboração de } \\
\text { projeto do } \\
\text { canteiro }\end{array}$ & Não participação & Não identificado \\
\hline 8 & Resultados & Não identificado & Não participação & Não identificado & Não identificado & Não participação & Não identificado \\
\hline
\end{tabular}


Nas Empresas G e H não foi observada ou relatada a implantação de nenhuma prática. A Empresa $G$ contava com engenheiro de segurança em tempo parcial e apresentou no período alta rotatividade de seus técnicos de segurança. Os dois técnicos de segurança que participaram do ambiente colaborativo já haviam sido desligados da empresa quando da realização das entrevistas finais. $\mathrm{O}$ representante da produção entrevistado ressaltou sua ênfase nas questões específicas da produção. Embora considerasse a segurança importante, faltava alguém da empresa para liderar o processo. Esse fato pode ter inibido a introdução de práticas, especialmente considerando que a direção da empresa apoiava tais iniciativas.

Já na Empresa H o principal motivo pelo resultado foi provavelmente a descrença de seu engenheiro de segurança. Esse fato, por exemplo, fez com que o setor de pessoas da empresa indicasse como representante da produção um estagiário de administração de empresas, e como representante da segurança um auxiliar técnico de enfermagem do trabalho. Estes profissionais, por consequência, apesar da tentativa de disseminação das informações, dispunham de baixo poder de decisão para a introdução de melhorias.

De uma maneira geral, as práticas implantadas pelas empresas foram relacionadas com investimentos na gestão de segurança e em melhorias nas proteções coletivas e equipamentos. A contratação ou realocação de profissionais pelas empresas também foi um fato de destaque, particularmente nas Empresas C e D. Além disso, as práticas implantadas, especialmente pelas Empresas B e E, se caracterizaram pelo baixo investimento, enquanto nas Empresas C, D e F notou-se a implantação de práticas de maior investimento. A Empresa B, por exemplo, conseguiu avanços importantes, sobretudo pelas práticas internas de disseminação de conhecimentos e pelo esforço de seus especialistas de SST.

Também foram identificadas ações decorrentes da participação das empresas no ambiente colaborativo. As Empresas A e C demandaram ao coordenador do ambiente colaborativo a participação em outro projeto motivado pelo tema do encontro 7 (interação segurança e produção). Especificamente na Empresa A ocorreu a publicação de diversos informativos, em mídias internas e externas à empresa, que mencionavam sua participação no projeto. Já a Empresa B disseminou ideias testadas em um canteiro para as demais obras da empresa. Na Empresa D percebeu-se maior autonomia na atuação dos técnicos de segurança diante de situações irregulares. Já na Empresa $F$ houve a aquisição de elevadores cremalheiras em substituição aos de cabo.

\section{Fatores contribuintes para a disseminação de práticas de SST}

A disseminação de práticas por meio de ambientes colaborativos pode ser considerada um processo complexo, no sentido de que são vários os fatores intervenientes, algumas vezes concorrentes e dependentes, que atuam simultaneamente, de forma a contribuir, ou não, para o sucesso do resultado final. Em função da realidade de cada empresa, um ou outro fator pode ser predominante, apesar de que outros, ainda que em menor grau, também contribuam.

A seguir são descritos os fatores que contribuíram para a disseminação de práticas de SST, identificados neste estudo, iniciando-se pelos fatores mais abstratos em direção aos fatores mais objetivos. Cada um dos fatores está ilustrado com as evidências mais marcantes quanto a comportamentos e ações das empresas, observados durante a etapa de coleta e análise dos dados.

\section{Cultura de SST}

A cultura de segurança pode representar um fator que contribui para a disseminação de práticas de SST, dependendo da força de sua presença na organização. Ela diz respeito a tudo aquilo que afeta as atitudes e os comportamentos das pessoas em relação à SST (COOPER, 2000; VIEIRA; SILVA JUNIOR; SILVA, 2014). Reason (1997) discute os principais componentes de uma cultura de segurança e aponta quatro críticos: participação, flexibilidade, compartilhamento e aprendizado.

A cultura de participação vai depender de como a organização considera as questões ligadas à responsabilidade pelos fatos e possíveis punições (cultura da justiça). Assim, não se deseja uma cultura de julgamento e punição, mas uma cultura que analisa os fatos como forma de aprendizado (cultura do aprendizado). Além disso, a organização deve desenvolver uma cultura de flexibilidade como forma de se adaptar às constantes mudanças da sociedade atual. Por fim, a cultura do compartilhamento de conhecimento (difusão de informações) garantirá que todos os elementos do sistema estarão cientes dos perigos e medidas de prevenção adotadas. No entanto, para Nunes (2012) e Schmitt (2012), as atitudes e crenças existentes na cultura interna das empresas estão entre as principais dificuldades para o compartilhamento do conhecimento. 
A observação dos comportamentos das empresas participantes apresenta evidências que possibilitam refletir sobre a influência da cultura de segurança no processo de disseminação de práticas, como exemplificam os casos das Empresas A e $\mathrm{H}$.

A Empresa A, por exemplo, demonstrou comportamentos que evidenciam forte cultura de participação, aprendizado e difusão de informações em relação a SST, como descrito anteriormente. Por outro lado, na Empresa H não houve a mesma intensidade de participação e comprometimento na disseminação de práticas. O gestor de segurança, além de contratado de forma terceirizada, demonstrou atitude de descrença em relação ao aprendizado colaborativo e resistência ao compartilhamento de conhecimentos, repercutindo, por exemplo, nas ausências dos técnicos e gestores diretamente envolvidos com a segurança e a produção durante os encontros do ambiente colaborativo.

\section{Comprometimento da alta direção}

O comprometimento da alta direção é outro fator observado que pode contribuir para a disseminação de práticas de SST nas empresas. Embora os diretores das empresas não tenham participado diretamente das ações do ambiente colaborativo, percebeu-se, particularmente em dois casos das Empresas A e D, que o suporte e apoio dado pela alta direção no provimento de recursos, financeiros ou não, influenciaram positivamente a participação dos representantes no projeto e a disseminação de práticas.

Em contrapartida, nas Empresas B e E a falta de comprometimento da direção pode ter sido uma barreira para a maior disseminação de práticas. Os resultados identificados nestas duas empresas basearam-se unicamente nas ações autônomas de seus representantes, portanto limitados a seu poder de ação e decisão.

A importância do comprometimento da alta direção foi apontada nas entrevistas como um dos fatores de maior relevância no processo de disseminação de práticas. De fato, a literatura também aponta esse fator como facilitador do processo. Nunes (2012), por exemplo, considera que o comprometimento dos diretores é demonstrado através de:

(a) liberação dos profissionais para a participação nos encontros;

(b) planejamento e disponibilização de recursos;

(c) abertura de espaço para discussão interna sobre as práticas apresentadas; e (d) auxílio no estabelecimento de uma cultura organizacional de compartilhamento do conhecimento.

\section{Capacidade de aprendizagem interna da empresa}

Tomando por base o conceito de capacidade de absorção proposto por Cohen e Levinthal (1990), pode-se analisar a capacidade de aprendizagem da empresa como um dos fatores de impacto na absorção de práticas. Cohen e Levinthal (1990) definem a capacidade de absorção como a capacidade da empresa de reconhecer o valor de uma informação externa, assimilá-la e aplicá-la em seu contexto. Isso está ligado ao conhecimento ou competências já existentes na empresa sobre o assunto e também em sua capacidade de explorar e experimentar o conhecimento (HUGHES et al., 2014).

Dessa forma, as estruturas formais e informais de comunicação interna, a abertura e autonomia das pessoas para experimentar novos conhecimentos e ações são fatores que interferem na capacidade de aprendizagem da empresa. Nesse âmbito pode-se apontar como evidências desses comportamentos na Empresa D: participação direta do diretor da empresa e o valor atribuído à questão da segurança; criação de mecanismos internos para divulgação do conhecimento adquirido no ambiente colaborativo por toda a empresa; e autonomia dada aos gestores e técnicos de segurança para experimentação e implantação das práticas nos canteiros de obra.

\section{Características dos representantes das empresas nos encontros}

O estudo do ambiente colaborativo sugere que os representantes das empresas nos encontros devem dispor de certas competências e poder de decisão para que seja alcançado o sucesso na disseminação de práticas, bem como habilidade para fazer com que as informações adquiridas possam ser difundidas e absorvidas por outras pessoas na empresa. A seleção dos representantes deve considerar o perfil e os conhecimentos prévios deles. A participação de pessoas com domínio básico dos temas abordados e com um bom relacionamento interpessoal foram características que facilitaram disseminação de conhecimentos. Além disso, os representantes precisam acreditar no projeto e estar motivados para servir de multiplicadores nas empresas.

Nessa discussão, Nunes (2012) destaca o conjunto de conhecimentos que os representantes já dispõem, tais como a terminologia e as ferramentas 
relacionadas aos temas discutidos, como um dos principais fatores para o sucesso na troca de conhecimentos nos ambientes colaborativos. Além disso, os representantes deverão ser reconhecidos corporativamente pelo excelente relacionamento interpessoal com seus pares e equipes, e pelo papel de formadores de opinião que exercem em sua área de atuação. Da mesma forma, como afirmam Cohen e Levinthal (1990), a capacidade de absorção da empresa depende da capacidade do indivíduo que faz a interface entre o ambiente externo e a organização, tendo este um papel fundamental na tradução do conhecimento adquirido externamente ao contexto da empresa.

Entretanto, em que pesem essas características, elas não serão suficientes nos casos em que os representantes não tenham acesso e respaldo da alta direção. Como evidências pode-se citar os casos das Empresas A, C, D e F, nas quais a presença de especialistas em segurança, em particular, com poder de decisão e apoio da diretoria foi importante para a disseminação de práticas. Por outro lado, nas Empresas C e F o baixo envolvimento dos representantes da produção refletiu em resistências e maiores dificuldades nas ações pretendidas pelos especialistas de segurança.

\section{Consolidação do SESMT na empresa}

A presença de especialistas de segurança na empresa e, em decorrência, de um SESMT consolidado e com um gestor atuante e dedicado à empresa pode ser observada como um fator que contribuiu para a disseminação de práticas nas empresas. Pode-se supor que a reduzida disseminação de práticas nas Empresas E, G e H reflita a necessidade de consolidação do SESMT, em especial através da contratação de um gestor que possa liderá-lo de forma efetiva e presente. As Empresas E e H, coincidentemente, contavam com os serviços (em tempo parcial) do mesmo engenheiro de segurança, o qual declarou não acreditar nos objetivos do projeto.

A Empresa G também contava com os serviços de um engenheiro de segurança (contratado por tempo parcial) e técnicos de segurança com pouco tempo de atuação na empresa. A instabilidade do quadro dos técnicos de segurança, as frequentes ausências nos encontros e o reduzido tempo de envolvimento do engenheiro de segurança com a empresa pressupõem a ausência de uma liderança no SESMT dessa empresa, o que justifica a baixa disseminação de práticas.

Em contrapartida, as Empresas A e C, por exemplo, apresentaram SESMT consolidado e atuante, com a presença de gestores ativos e presentes nos processos internos delas.

\section{Momento econômico e estrutural das empresas}

A disseminação de práticas também pode ser inibida pelo momento econômico da empresa, assim como por sua estrutura interna. As evidências sugerem que, diante de uma conjuntura econômica favorável, a empresa pode optar pela realização de investimentos na área, tal como ocorreu na Empresa $\mathrm{C}$, que alocou um técnico para auxiliar na gestão da segurança, e na Empresa D, com os diversos investimentos realizados.

Por outro lado, o momento econômico e estrutural (proximidade de ser fundida com outra construtora) da Empresa A repercutiu em seu desempenho. No entanto, segundo um de seus gerentes, o projeto serviu para movimentar a empresa, fazendo com que novas ações de melhorias fossem discutidas dentro de sua realidade atual.

Outras empresas, tais como E e G, apresentavam estruturas internas bem enxutas, com profissionais que desempenhavam várias funções, não necessariamente no campo de suas formações. Dessa forma, a falta de uma liderança para conduzir o processo de transferência pode ter ocorrido em função da sobrecarga de trabalho dos profissionais da empresa. A Empresa D foi o bom exemplo, pois, ainda que com uma estrutura reduzida de pessoas, dividiu as atribuições de um arquiteto, com especialização em engenharia de segurança, que atuava exclusivamente no setor de projetos, entre as duas áreas (projeto e gestão de segurança).

\section{Participação de profissionais afins ao tema do encontro}

Apesar de as empresas terem suas representações fixas durante os encontros, percebeu-se a relevância da participação de outros profissionais delas afins ao tema proposto, na intenção de facilitar o processo de transferência de práticas.

Dessa forma, ao tratar de temas específicos, a presença de profissionais especializados tornou mais valioso o processo de compartilhamento do conhecimento. Foi o caso, por exemplo, ocorrido no encontro 3, em que a Empresa B enviou seu engenheiro mecânico, juntamente com seus representantes, para participar da visita técnica e discussões sobre máquinas e equipamentos. Esse fato facilitou a disseminação de práticas relacionadas particularmente com elevadores naquela empresa. 


\section{Estruturação dos canais formais de comunicação na empresa}

Observou-se igualmente ao longo do desenvolvimento do ambiente colaborativo a importância da estruturação de canais formais de comunicação visando aumentar a disseminação de práticas na empresa. Dessa forma, os conhecimentos adquiridos não ficam restritos a algumas pessoas ou obras específicas. Esses canais internos de comunicação devem privilegiar as informações técnicas acerca das práticas, não se atendo somente em divulgá-las de forma genérica.

Nesse sentido pode-se observar, no caso da Empresa G, que não havia canais de comunicação formal, e quando todos os seus representantes da área de segurança foram desligados da empresa houve prejuízo na disseminação das práticas. Já a Empresa B adotou a prática de, logo após os encontros, seus representantes divulgarem as informações adquiridas para os especialistas em SST. Além disso, nesta mesma empresa, as práticas eram testadas e, em seguida, elaborava-se um relatório com a descrição e detalhes técnicos delas, visando à aplicação nos demais canteiros.

\section{Auxílio dispensado pela empresa de referência às demais}

Observou-se que nem sempre as apresentações e discussões durante os encontros foram suficientes para se alcançar efetiva disseminação das práticas. Foram criados ao longo do processo canais informais de troca e comunicação, ou seja, ocorreram trocas de conhecimento fora do contexto formal dos encontros do ambiente colaborativo. Nesse sentido, a postura positiva de auxílio dispensada pelas empresas de referência, ou seja, aquelas responsáveis por apresentar as práticas já implantadas, tornou-se fator relevante.

Nesse sentido, alguns casos puderam ser observados nos quais os representantes das empresas buscaram, através de contatos fora dos encontros presenciais, as contribuições das empresas de referência. Por exemplo, no processo de aquisição de elevadores cremalheiras pela Empresa F houve troca de conhecimentos de seu engenheiro de segurança com colegas de outras empresas com experiência no uso daqueles equipamentos. Em outro caso, o gerente de produção da Empresa G, por exemplo, solicitou os contatos de colegas de outras empresas para que pudessem se aprofundar em algumas práticas. Esse fato, em especial, evidenciou a necessidade de se criarem outros canais de interação entre os participantes, visando facilitar as trocas entre as empresas.

\section{Condução dos encontros presenciais}

Identificou-se que a condução dos encontros presenciais é outro fator crítico para a disseminação de práticas de SST entre as empresas (HERNANDES, 2003; NUNES, 2012). A forma como o ambiente foi conduzido, bem como a escolha dos temas (de interesse das empresas, particularmente por se tratar de requisitos de cumprimento obrigatório), a proposta de um mix de ações realizadas (visitas técnicas, palestras, apresentações de casos, mesas-redondas e atividades motivadoras) e o direcionamento das discussões representaram elementos importantes para o processo de transferência.

Particularmente nas empresas de referência o processo de questionamento entre os membros do grupo refletiu em melhorias de suas práticas, tal como percebido na Empresa C, que revisou procedimentos já consolidados das linhas de vida em função do questionamento do grupo.

\section{Considerações finais}

Este estudo identificou dez fatores que contribuem para a disseminação de práticas SST compartilhadas por meio de ambientes colaborativos de aprendizagem entre empresas de construção. Trata-se de um processo complexo no sentido de que são vários os fatores intervenientes, algumas vezes concorrentes e dependentes, que atuam simultaneamente, de forma a contribuir, ou não, para o sucesso do resultado final. Em função da realidade da empresa, um fator pode ser predominante, apesar de outros, ainda que em menor grau, também poderem contribuir.

Para a consolidação ou revisão dos fatores identificados é importante, por exemplo, novas investigações a partir da criação e operação de outros ambientes colaborativos voltados à prevenção de acidentes do trabalho. A realização de estudos em ambientes que englobam um maior número de empresas participantes e de encontros realizados, e posterior análise das práticas implantadas, pode trazer contribuições que reforcem ou não a validade dos fatores propostos. Além disso, novos estudos podem ser direcionados a investigar com maior rigor e profundidade a influência da participação, ou não, de representantes da produção no processo, uma vez que no ambiente colaborativo estudado algumas empresas disponibilizaram apenas representantes da segurança. Outra sugestão diz respeito a desenvolver avaliações sistemáticas, com estruturas metodológicas rigorosas, para analisar o nível de implantação das práticas de gestão de 
segurança transferidas às empresas por intermédio de ambientes colaborativos.

\section{Referências}

AWWAD, R.; EL SOUKI, O.; JABBOUR, M. Construction Safety Practices and Challenges in a Middle Eastern Developing Country. Safety Science, v. 83, p. 1-11, 2016.

BALESTRIN, A.; VERSHOORE, J. R. Redes de Cooperação Empresarial. Porto Alegre: Bookman, 2008.

BESSANT, J.; TSEKOURAS, G. Developing Learning Networks. AI\&Society, v. 15, n. 1-2, p. 82-98, mar. 2001.

BRASIL. Ministério da Previdência Social. Quantidade de Acidentes do Trabalho, Por Situação de Registro e Motivo, Segundo o Setor de Atividade Econômica - 2009/2011, 2011 b. Disponível em:

<http://www.previdencia.gov.br/conteudoDinamic o.php?id=1546>. Acesso em: 18 ago. 2013.

BRASIL. Ministério do Trabalho e Emprego. Relação Anual de Informações Sociais (RAIS). RAIS 2011 - Evolução do Emprego Formal, 2011a. Disponível em:

<http://portal.mte.gov.br/rais/estatisticas.htm>. Acesso em: 18 ago. 13.

BRASIL. Ministério do Trabalho. Norma Regulamentadora 18 (NR-18). Portaria GM n ${ }^{\circ}$ 3.214 , de 8 de junho de 1978. Última atualização dada pela Portaria MTPS $n^{\circ} 208$, de 8 de dezembro de 2015. Disponível em:

<http://trabalho.gov.br/images/Documentos/SST/N R/NR18/NR18atualizada2015.pdf >. Acesso em: 13 mar. 2017.

BRIDI, M. E. et al. Identificação de Práticas de Gestão da Segurança e Saúde no Trabalho em Obras de Construção Civil. Ambiente Construído, Porto Alegre, v. 13, n. 3, p. 43-58, jul./set. 2013.

BRITTO, J. Cooperação Tecnológica e Aprendizado Coletivo em Redes de Firmas: sistematização de conceitos e evidências empíricas. In: ENCONTRO NACIONAL DE ECONOMIA, 29., Salvador, 2001. Anais... Salvador: Anpec, 2001

CAMBRAIA, F. B. et al. Diretrizes Para Estruturação de Ambientes Colaborativos Para Troca de Práticas de Prevenção aos Acidentes do Trabalho na Construção. In: SIMPÓSIO BRASILEIRO DE GESTÃO DA ECONOMIA DA CONSTRUÇÃO, 8., Salvador, 2013. Anais..., Salvador: SIBRAGEC, 2013.
COHEN, W. M.; LEVINTHAL, D. A. Absorptive Capacity: a new perspective on learning and innovation. Administrative Science Quartely, v. 35, n. 1, p. 128-152, mar. 1990.

COOPER, M. D. Towards a Model of Safety Culture. Safety Science, Amsterdam, v. 36, n. 2, p. 111-136, nov. 2000.

COSTA, D. B.; FORMOSO, C. T. Fatores-Chave de Sucesso Para Sistemas de Indicadores de Desempenho Para Benchmarking Colaborativo Entre Empresas Construtoras. Ambiente Construído, Porto Alegre, v. 11, n. 3, p. 143-159, jul./set. 2011.

COSTA, D. Diretrizes Para a Realização de Processo de Benchmarking Colaborativo Visando a Implementação de Melhorias em Empresas de Construção Civil. Porto Alegre, 2008. Tese (Doutorado em Engenharia Civil) Programa de Pós-Graduação em Engenharia Civil, Universidade Federal do Rio Grande do Sul, Porto Alegre, 2008.

ELKJAËR, B. In Search of a Social Learning Theory. In: EASTERBY, S.; M. BURGOYNE, J.; ARAUJO, L. (Eds.). Organizational Learning and the Learning Organization: developments in theory and practice. London: Sage, 1999. =

FLORÉN, H. Collaborative Approaches to Management Learning in Small Firms. Journal of Workplace Learning, v. 15, n. 5, p. 203-216, 2003.

FREITAS, A. A. F.; HEINECK, L. F. M. Acumulação de Capacidades Tecnológicas: evidências em empresas de construção civil constituintes de uma rede de aprendizagem. Ambiente Construído, Porto Alegre, v. 14, n. 2, p. 7-21, abr./jun. 2014.

HERNANDES, C. A. M. Fatores Críticos de Sucesso Para o Estabelecimento e a Operação de Comunidades de Prática Virtuais. Brasília, 2003. Dissertação - Programa de Pós-Graduação em Gestão do Conhecimento e da Tecnologia da Informação, Universidade Católica de Brasília, Brasília, 2003.

HINZE, J. Making Zero Injuries a Reality: a report to the Construction Industry Institute. University of Florida, Gainesville, 2002.

HUGHES, M. et al. Social Capital and Learning Advantages: a problem of absorptive capacity. Strategic Entrepreneurship Journal, v. 8, n. 3, p. 214-233, sept. 2014.

LAVE, J.; WENGER, E. Situated Learning: legitimate peripheral participation. New York: Cambridge Press, 1991. 
MALLMANN, B. S. et al. Avaliação do Atendimento aos Requisitos da NR-18 em Canteiros de Obra. In: SIMPÓSIO BRASILEIRO DE GESTÃO DA ECONOMIA DA CONSTRUÇÃO, 6., João Pessoa, 2009. Anais..., João Pessoa: SIBRAGEC, 2009.

MILES, M. B.; HUBERMAN, A. M. Qualitative Data Analysis: an expanded sourcebook. 2. ed. Thousand Oaks: Sage, 1994.

NONAKA, I.; TAKEUCHI, H. Criação do Conhecimento na Empresa. Rio de Janeiro: Campus, 1997.

NUNES, I. H. Diretrizes Estratégicas Para o Desenvolvimento de Comunidades de Prática na Área Comercial de uma Empresa de Distribuição de Energia Elétrica. Florianópolis, 2012. Tese (Doutorado em Engenharia e Gestão do Conhecimento) - Programa de Pós-Graduação em Engenharia e Gestão do Conhecimento, Universidade Federal de Santa Catarina, Florianópolis, 2012.

PETER, L. D. et al. Collaboration and Collective Learning: networks as learning organizations. Journal of Business \& Industrial Marketing, v. 25 , n. 6 , p. $478-84,2010$.

POPP, J. et al. Inter-Organizational Networks: a critical review of the literature to Inform practice. 2013. Disponível em:

<http://www.research4children.com/data/documen ts/NetworkLiReview-Feb27-2013-Final.pdf>. Acesso em: 29 ago. 2016.

RAZURI, C. Un Sistema Integrado de Gestión de Producción y Seguridad en la Construcción. Chile, 2007. Tesis (Magíster en Ciencias de la Ingeniería) - Escuela de Ingeniería, Universidad Católica de Chile, Santiago, Chile, 2007.

REASON, J. Managing the Risk of Organization Accidents. Burlington: Ashgate, 1997.
SAURIN, T. A.; LANTELME, E; FORMOSO, C. T. Contribuições Para Aperfeiçoamento da NR18: condições e meio ambiente de trabalho na indústria da construção. Porto Alegre:

Universidade Federal do Rio Grande do Sul, 2000. Relatório de Pesquisa.

SCHMITT, S. R. Fatores Críticos de Sucesso à Manutenção de Comunidades de Prática e Suas Dimensões de Análise. Florianópolis, 2012.

Dissertação (Mestrado em Engenharia e Gestão do Conhecimento) - Programa de Pós-Graduação em Engenharia do Conhecimento, Universidade Federal de Santa Catarina, Florianópolis, 2012.

SOUZA, J. Aprendizagem Organizacional: desafios e perspectivas ao desenvolvimento de comunidades de prática. Salvador: Conhecimento Superior, 2007.

VIEIRA, M. A; SILVA JUNIOR, A.; SILVA, P. O. M. Influências das Políticas e Práticas de Gestão de Pessoas na Institucionalização da Cultura de Segurança. Production, v. 24, n. 1, p. 200-211, jan./mar. 2014.

WOOD, D.; GRAY, B. Towards a Comprehensive Theory of Collaboration. Journal of Applied Behavioural Science, v. 27, n. 2, p. 139-162, 1991.

YIN, R. K. Estudos de Caso: planejamento e métodos. Bookman: Porto Alegre, 2005.

\section{Agradecimentos}

Ao Programa Institucional de Bolsas de Iniciação à Extensão (PIBIX/UFS); ao Sinduscon/SE; à Superintendência Regional do Trabalho e Emprego do Estado de Sergipe (SRTE/SE); e às empresas e profissionais participantes do estudo. 


\section{Fabricio Borges Cambraia}

Departamento de Construção Civil, Faculdade de Engenharia | Universidade Federal de Juiz de Fora | Quarta Plataforma do Setor de Tecnologia, Campus da UFJF | Juiz de Fora - MG - Brasil | CEP 36036-330 | Tel.: (32) 2102-3411 | E-mail:

fabricio.cambraia@engenharia.ufjf.br

\section{Thales William Santana dos Santos}

Gerência de Controle de Perdas | Companhia de Saneamento de Sergipe | Rua Campo do Brito, 331, Treze de Julho | Aracaju - SE - Brasil | CEP 49020-380 | Tel.: (79) 3226-1169 | E-mail: eng.thaleswsantos@outlook.com

\section{Elvira Maria Vieira Lantelme}

Curso Engenharia Civil | Faculdade Meridional | Rua Senador Pinheiro, 304, Vila Rodrigues | Passo Fundo - RS - Brasil | CEP $99070-220$ |

Tel.: (54) 3045-6100 | E-mail: elvira.lantelme@imed.edu.br

\section{Revista Ambiente Construído}

Associação Nacional de Tecnologia do Ambiente Construído

Av. Osvaldo Aranha, $99-3^{\circ}$ andar, Centro

Porto Alegre - RS - Brasil

CEP $90035-190$

Telefone: +55 (51) 3308-4084

Fax: +55 (51) 3308-4054

www.seer.ufrgs.br/ambienteconstruido

E-mail: ambienteconstruido@ufrgs.br 